\title{
Relationship between Video Game Violence and Long-Term Neuropsychological Outcomes
}

\author{
Yoshiyuki Tamamiya, Goh Matsuda, Kazuo Hiraki \\ Graduate School of Arts and Sciences, The University of Tokyo, Tokyo, Japan \\ Email: tamamiya@ardbeg.c.u-tokyo.ac.jp
}

Received 31 June 2014; revised 28 July 2014; accepted 21 August 2014

Copyright (C) 2014 by authors and Scientific Research Publishing Inc.

This work is licensed under the Creative Commons Attribution International License (CC BY). http://creativecommons.org/licenses/by/4.0/

\section{(c) (i) Open Access}

\begin{abstract}
The current study examined the long-term effects of video game violence on aggressiveness and facial expression recognition using multiple measures. In Experiment 1, participants unfamiliar with video games were randomly assigned to play a violent or nonviolent video game for four weeks. Before and after the game play interval, event-related potentials (ERP) evoked by facial expressions were recorded, and aggressiveness was measured with a questionnaire. Results showed that playing a violent video game delayed peak latency of a positive component of the ERP evoked by angry faces and increased aggressiveness among male participants. Experiment 2 included a 3-month follow-up assessment. Results showed preservation of delayed neural activity, while levels of aggressiveness diminished to some extent. These findings highlight differential aspects regarding the long-term effects of playing a violent video game: more enduring for facial expression recognition and short-lived for aggressiveness.
\end{abstract}

\section{Keywords}

Violent Media, Facial Expression Recognition, Aggression, Event-Related Potential (ERP)

\section{Introduction}

Several studies have assessed the negative effects of exposure to media violence (see Anderson et al., 2003). As video games have become more popular, various studies have examined the negative effects of exposure to video game violence (see Anderson et al., 2010). Past research has shown that exposure to game violence is linked to increased levels of aggression (Anderson \& Dill, 2000), hostile expectations (Bushman \& Anderson, 2002), and lower empathy (Funk, Baldacci, Pasold, \& Baumgardner, 2004). Some studies have also examined the in- 
fluence of exposure to game violence and perceptual facial expression processing (Kirsh \& Mounts, 2007; Kirsh, Mounts, \& Olczak, 2006). Results have indicated that playing violent video games induces negative processing biases when recognizing facial emotion.

Despite the aforementioned evidence, two important questions remain. First, most studies have focused on the short-term effects of violent video game exposure (Devilly, Callahan, \& Armitage, 2012). In such studies, participants are asked to play violent video games over a brief interval (e.g., only a few minutes to an hour). Though some studies have examined extended exposure to violent video games (e.g., three days), the total time spent playing is modest (e.g., 1 total hour over 3 days; Hasan, Bègue, Scharkow, \& Bushman, 2012). Most video gamers play for more than a few hours at a time, maybe even more than 100 hours for any specific game, especially popular video games containing violence (e.g., Call of Duty or the Grand Theft Auto series). Thus, merely a few minutes of play are not sufficient to examine the actual effects of exposure to these video games. Though some correlational research has examined longitudinal effects of playing violent video games (Anderson et al., 2008; Thori, Sakamoto, Kobayashi, \& Kimura, 2003; Wallenius \& Punamäki, 2008), no experimental study has investigated the long-term effects of violent video games. Given that digital devices, such as smart phones and tablet PCs, allow individuals to play video games anytime and anywhere, it is important to further address questions as to whether long-term exposure to violent video games leads to substantial negative outcomes.

Second, to more clearly understand the effects of exposure to game violence, cognitive neuroscientific methods should be included to examine how exposure to video game violence affects neural processes. This is because higher-order cognitive processes regarding the interpretation and assessment of video game violence on negative outcomes have generally been measured via questionnaires. This likely masks the actual effects of video game violence on psychological processes (Staude-Müller, Bliesener, \& Luthman, 2008). As Lang (2006) pointed out, it is important to examine both how people process media messages and how the media affects information processing. For instance, one functional magnetic resonance imaging (fMRI) study showed that playing a violent video game suppresses limbic neural structures associated with emotional information processing (Weber, Ritterfield, \& Mathiak, 2006). Previous studies using event-related brain potentials (ERP) have provided additional evidence suggesting that repeated exposure to media violence is linked to a desensitization to violence (Bailey, West, \& Anderson, 2011; Bartholow, Bushman, \& Sestir, 2006), and this desensitization mediates the effect of video game content on subsequent aggressive behavior (Engelhard, Bartholow, Kerr, \& Bushman, 2011). There is also evidence indicating that video game violence induces physiological desensitization to violence, indexed by changes in heart rate and galvanic skin responses (Carnage, Anderson, \& Bushman, 2007). However, no experimental study to date has explored the long-term effects of exposure to media violence on the neural processing of facial expressions. Thus, the present study examined the effects of early ERP components on the visual domain, the occipitotemporal N170, and P2. The N170 is a large posterior negative deflection that follows the visual presentation of a facial picture, peaking at occipitotemporal sites at around $170 \mathrm{~ms}$ (Bentin, Allison, Puce, Perez, \& McCarthy, 1996). A number of fMRI studies have shown that the source of the N170 is centered on the fusiform gyrus and superior temporal gyrus (Horovitz, Rossion, Skudlarski, \& Gore, 2004). One previous study observed a positive potential with a mean peak latency at around $220 \mathrm{~ms}$, P2, which is associated with deeper processing of visual stimuli (Latinus \& Taylor, 2005) and is not directly associated with facial expression categorization (Tamamiya \& Hiraki, 2013). If playing violent video games affects the perceptual processing of facial expressions, the amplitudes or latencies of the N170 and P2 evoked by facial expressions should change after playing violent video games.

Recent studies have shown that video game training enhances many aspects of cognitive control (Green, Li, \& Bavelier, 2010). Moreover, these enhancements are associated with neuroplasticity (Anguera et al., 2013; Kühn et al., 2014). Given this evidence, it seems beneficial to assess the long-term effects of exposure to video game violence, specifically on a neuropsychological level.

The aim of the current study was to examine whether the long-term exposure to video game violence would affect facial expression recognition and aggressiveness, and if so, how long the effects of video game violence would last after the game play ceased.

\section{Experiment 1}

\subsection{Method: Participants}

Participants were recruited from local Japanese universities. Twenty-two healthy, right-handed Japanese volun- 
teers (10 females and 12 males, aged 18 - 29 years, mean age $=21.2, S D=3.44$ ) participated in the experiment. Participants were paid approximately 8000 yen. No participants had experience playing the video games used in the current study. Written informed consent was obtained from each participant before the experiment. The ethics committee of The University of Tokyo approved this study.

\subsection{Video Games}

All video games were played on PSP (PlayStation Portable), which allowed participants to play a video game at their convenience. The violent video game used in this study was "Grand Theft Auto: Liberty City Stories for PlayStation Portable” (GTA), and the nonviolent video game was "Boku no Natsuyasumi Portable: Mushi Mushi Hakase to Teppen-yama no Himitsu” (BOKUNATSU). GTA is an action-adventure video game. Players take on the role of a criminal who can roam freely around a big city. Various missions are set for completion such as bank robberies, assassinations, and other crimes. GTA contains frequent violent acts and scenes. BOKUNATSU is also an action-adventure video game. The player becomes a young boy who stays in the countryside during his summer vacation. The player can enjoy fishing, insect collecting, and talking with other characters. There is no violence in BOKUNATSU.

\subsection{Questionnaire}

Based on previous studies (Anderson \& Dill, 2000; Bartholow, Bushman, \& Sestir, 2006), a video game questionnaire was constructed. Participants were asked to list their five favorite video games and then rated each game on scales anchored from 1 to 7 in terms of how often they played each game and the violence portrayed in the game's content and graphics. Responses of 1 were labeled rarely no violent respectively. Responses of 7 were labeled often, extremely violent, respectively. For each participant, summing the violence content and violent graphics ratings, and multiplying this by the "how-often" rating, produced a violence exposure score for each participant's five favorite games. These five scores were averaged to form an overall index of video game violence exposure. The other focused on the amount of time spent playing each game, in general, computed by multiplying frequency, anchored at 1 (not at all) to 7 (everyday), by duration, anchored at 1 (1 to 15 minutes) to 7 (more than 3 hours). The range for general time spent playing a game was from 1 to 49 for each participant. Individual differences in aggressiveness were assessed using the Japanese version of the Buss-Perry Aggression Questionnaire (BAQ: Ando et al., 1999). The Japanese version of the BAQ includes 4 subscales: Physical Aggression (9 items; e.g., "If somebody hits me, I hit back”); Verbal Aggression (5 items; e.g., "My friends say that I'm somewhat argumentative”); Anger (7 items; e.g., "I have trouble controlling my temper”); and Hostility (8 items; e.g., "I am suspicious of overly friendly strangers”). Participants responded on scales anchored at 1 (This doesn't characterize me at all) to 5 (this characterizes me very well). Participants also rated an assigned video game on its level of violence, difficulty, fun, and action using 5-point scales ranging from 1 (strongly disagree) to 5 (strongly agree).

\subsection{Stimuli and Task}

Stimuli consisted of 10 photographs of facial expressions (a female and male posing angry, fearful, happy, sad, and neutral expressions) taken from the ATR Facial Expression Image Database (DB99). All stimuli were grayscale pictures. The protocol consisted of four blocks. Each block contained 120 facial stimuli, 24 for each expression and 6 target stimuli (a star). All photographs were $5.5 \times 8 \mathrm{~cm}$. The mean luminance was equal across stimuli. Stimuli were presented on a black background on a 17" CRT computer screen (EIZO FlexScan F520) at a viewing distance of $80 \mathrm{~cm}$ in front of the participants for $500 \mathrm{~ms}$ with an ISI of $1100 \mathrm{~ms}$ (see Figure 1). Participants were told that they would be shown a series of photographs and were asked to respond with a mouse click to the target stimulus (a star). The task was used to ensure that participants attended to the stimuli.

\subsection{Electrophysiological Recording and Analysis}

An electroencephalogram (EEG) was used to record ERP data from 65 electrodes with a Geodesic Sensor Net (Tucker et al., 1993) sampled at $250 \mathrm{~Hz}$ with a 1- to 100-Hz band-pass filter. Electrode impedance was below $100 \mathrm{k} \Omega$. All recordings were initially referenced to the vertex and later digitally re-referenced to the averaged reference. In the off-line analysis, a 30-Hz low-pass filter was reapplied. All data were segmented into 500-ms 


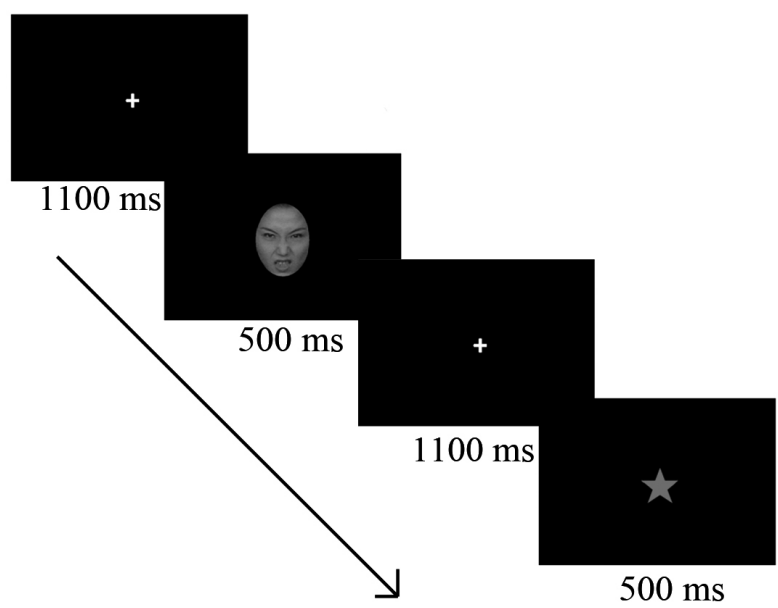

Figure 1. Time course of trials. Participants were instructed to respond only to a star.

epochs, including a 100-ms pre-stimulus baseline period, based on time markers for stimulus onset. Only segments less than $75 \mathrm{~V}$ in each channel were analyzed and baseline-corrected. Each component (N170, P2) was measured at the electrodes where the component was most prominent. N170 was measured at P7 and P8. P2 was measured at O1 and O2 (Latinus \& Taylor, 2005; Tamamiya \& Hiraki, 2013). Latencies were taken at the electrode where amplitude was maximal over each hemisphere, and amplitudes were measured at this latency.

\subsection{Procedure}

To examine the long-term effects of playing a violent video game, participants were assessed twice: before and after playing a video game. Each measurement time consisted of questionnaires and the EEG recording task. Thus, participants visited the laboratory a few times. After consent procedures were completed, baseline measurements were taken. Participants were randomly assigned to one of the two experimental conditions, and given a PSP with the assigned video game and told they would play the game for at least 4 hours a week, which would equate to 16 hours over the experimental period. After two weeks, participants were asked to visit the laboratory in order to demonstrate game progress. Within one week after playing the assigned video game for 16 hours, participants returned to the laboratory and completed the second measurements. Participants gave the assigned video game back to the researcher, and were asked not to play the game anymore.

\subsection{Results: Video Game Violence Exposure and Amount of General Time Spent Playing}

To compare participant's exposure to video game violence and amount of general time spent playing between the two conditions, a $2 \times 2$ (Video game [violent, nonviolent] $\times$ Gender [female, male]) analysis of variance (ANOVA) was conducted. None of the main effects or interactions reached significance ( $p s>.05$ ). In other words, there were no significant differences in exposure to video game violence or amount of time spent playing the games at baseline. The average amount of time spent, in general, playing games was low $(M=9.1$, the possible range of the scale is from 1 to 49), which indicated participants were not habitual game players as compared with a previous study (Carnagey et al., 2007).

\subsection{Video Game Ratings}

A $2 \times 2$ (Video game [violent, nonviolent] $\times$ Gender [female, male]) ANOVA was conducted. Ratings of game violence were affected by the type of game, $F(1,16)=235.64, p<.001, \eta_{p}^{2}=.94$. The violent game was rated as more violent $(M=4.8, S D=.42)$ than the nonviolent game $(M=1.2$, $S D=.63)$, which indicates that the chosen games did in fact differ in violent content. Ratings of game difficulty were also affected by game type, $F(1$, 16) $=38.72, p<.001, \eta_{p}^{2}=.71$, and gender, $F(1,16)=5.12, p=.038, \eta_{p}^{2}=.24$. The violent game was rated as more difficult $(M=4.4, S D=.70)$ than the nonviolent game $(M=2.2, S D=1.03)$. Female participants rated the video games as more difficult $(M=3.7, S D=1.25)$ than did male participants $(M=2.9, S D=1.52)$. The 
video game $\times$ gender interaction was significant in terms of game enjoyment ratings, $F(1,16)=7.78, p=.013$, $\eta_{p}^{2}=.33$. Female participants enjoyed the nonviolent game $(M=4.8, S D=.45)$ more than the violent game ( $M$ $=3.0, S D=1.23)$. Participants rated both games as equally action-packed $(p>.05)$. Given some of the significant effects of video game type in terms of difficulty and enjoyment, we used these variables as covariates in subsequent analyses. However, our main results were not affected by the addition of these covariates.

\subsection{BAQ}

Scores on the BAQ were analyzed using a $2 \times 2 \times 2$ (Video game [violent, non-violent] $\times$ Gender [female, male] $\times$ Measurement time [baseline, after playing the video game]) ANOVA. Results yielded a significant video game $\times$ measurement time $\times$ gender interaction, $F(1,18)=4.64, p=.037, \eta_{p}^{2}=.21$, on the Physical Aggression subscale (see Figure 2). This interaction revealed that male participants who played the violent game were more aggressive after playing the game $(M s=14.5$, and $16.8, S D s=5.47$ and 5.67$)$. No other significant effects on the BAQ subscales emerged.

\subsection{EEG}

Amplitudes and latencies of the N170 and P2 ERP components evoked by emotional expressions were analyzed (see Table 1). There was no significant effect on amplitudes and latencies of the N170 and amplitudes of the P2 for any expressions, $F s<3.90$, ps $>$.05. For the P2 latency over the left hemisphere site evoked by angry faces, the video game $\times$ measurement time interaction was significant, $F(1,18)=5.43, p=.032, \eta_{p}^{2}=.23$ (see Figure 3 and Figure 4). The P2 latency of participants playing a violent video game was longer after playing the game than at baseline ( $M s=232 \mathrm{~ms}$, and $242 \mathrm{~ms}$, SDs = 17.42 and 15.63). There was no significant effect on the P2 latency for other expressions, $F s<1.48$, $p s>.05$.

To investigate the relationship between increased aggressiveness and the delayed P2 latency, the difference scores for both variables between baseline and after game play were computed, and the association was examined. There was no significant correlation between increased aggressiveness and the delayed P2 latency ( $r$ $=.189, p=.40$ ); thus, the effects of playing a violent video game on angry facial expression recognition and aggressiveness were independent, respectively.

\subsection{Discussion}

The present experiment demonstrated that playing a violent video game over a longer time interval affects not only reported aggressiveness among players but also neural signatures related to emotional facial recognition. We were next interested in the persistence of these effects. Experiment 2 was conducted as a follow-up to assess the lasting effects of video game violence exposure over a period of a few months.

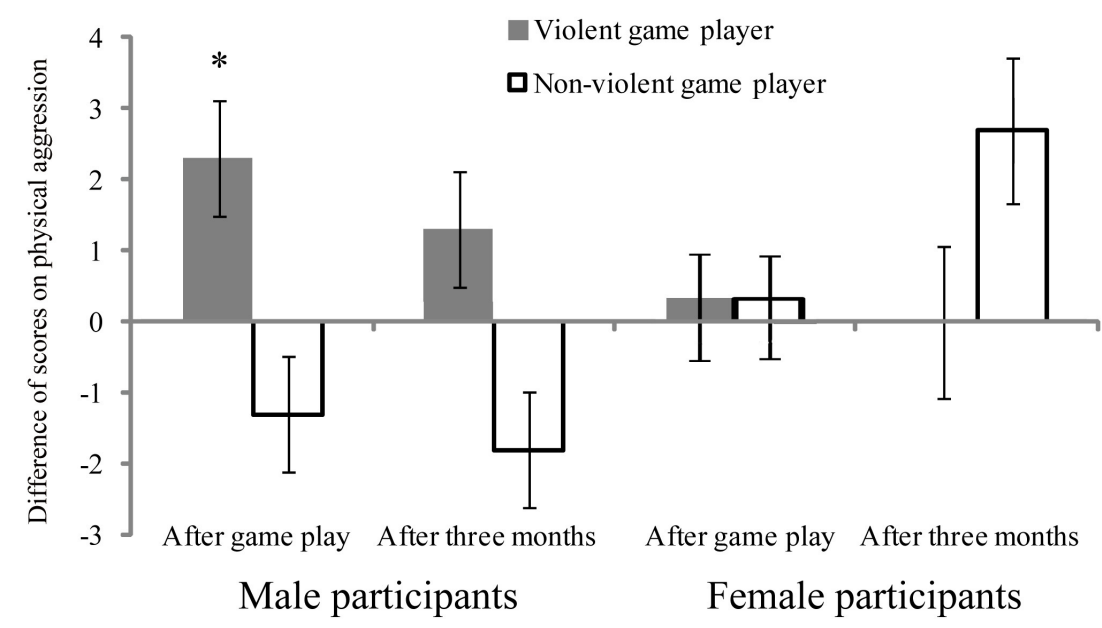

Figure 2. The effect of playing a video game on physical aggression. Each score was computed by subtracting aggression from baseline. A positive score indicates an increase in physical aggression from baseline. Error bars represent $\pm 1 \mathrm{SE}$. 


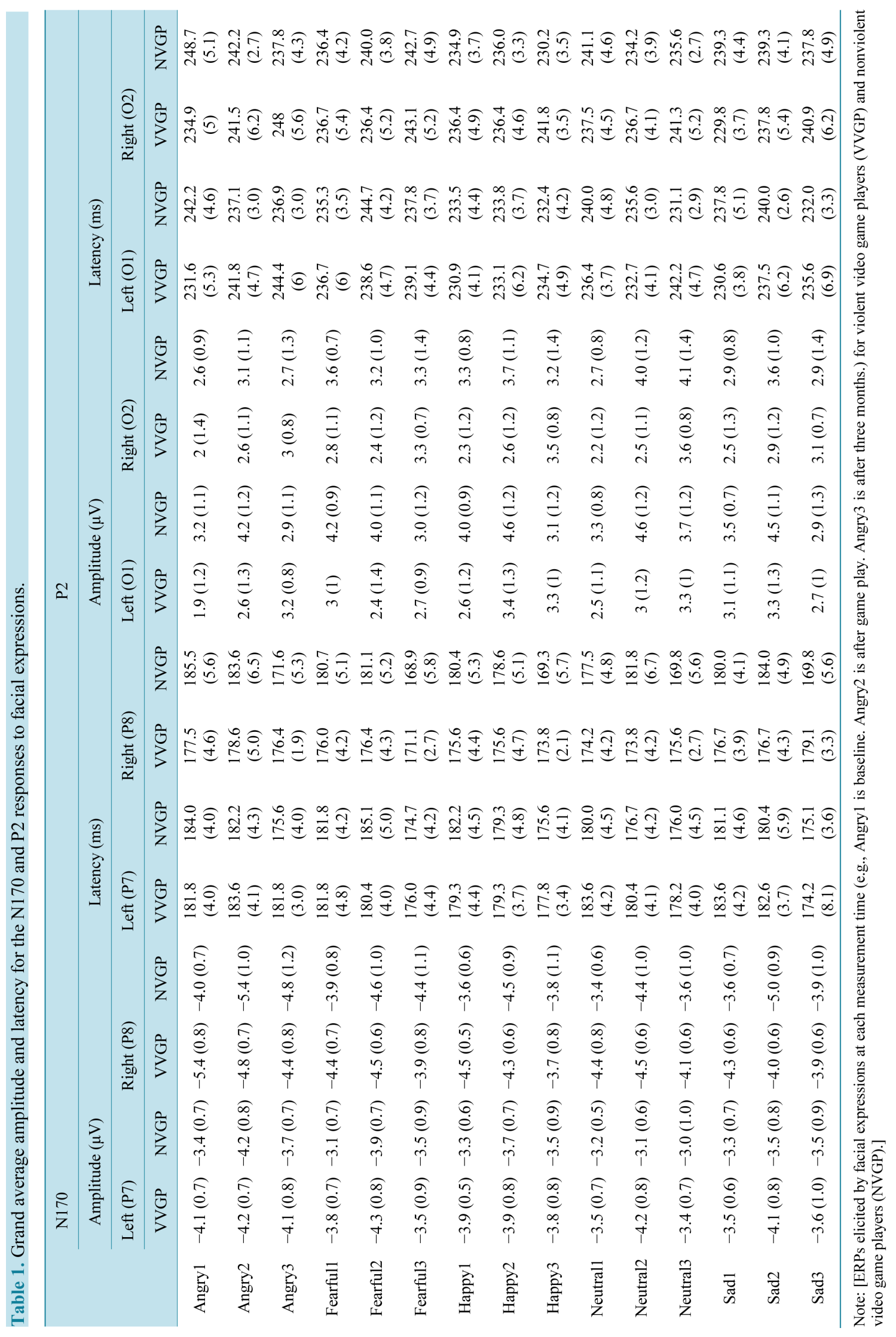


O1

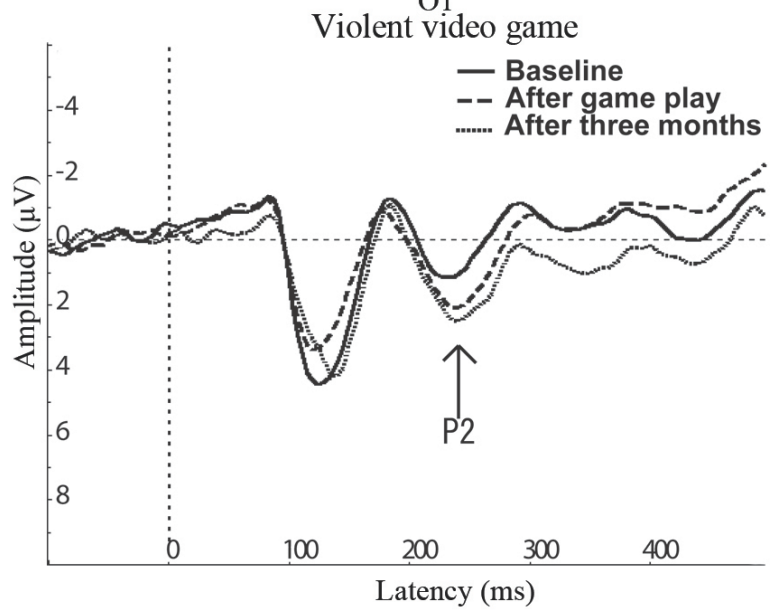

O1

Nonviolent video game

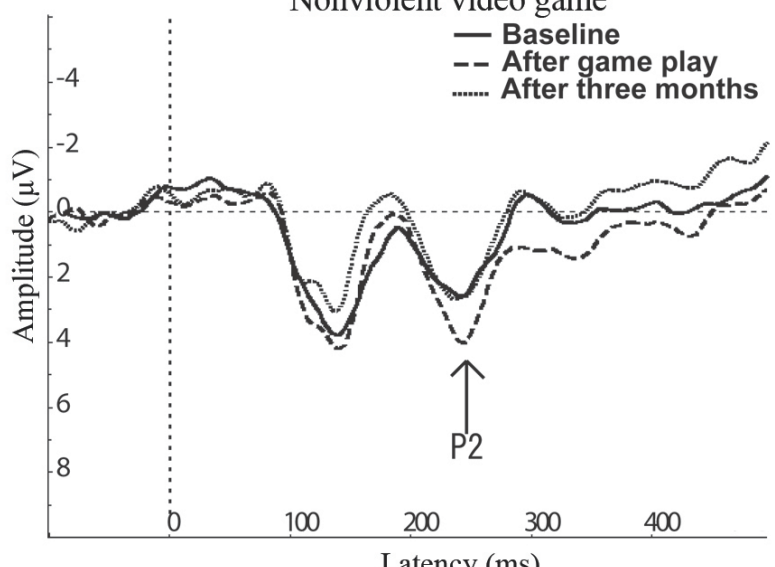

Latency (ms)

Figure 3. Grand average ERP waveforms evoked by angry faces. Electrode site O1 is displayed.

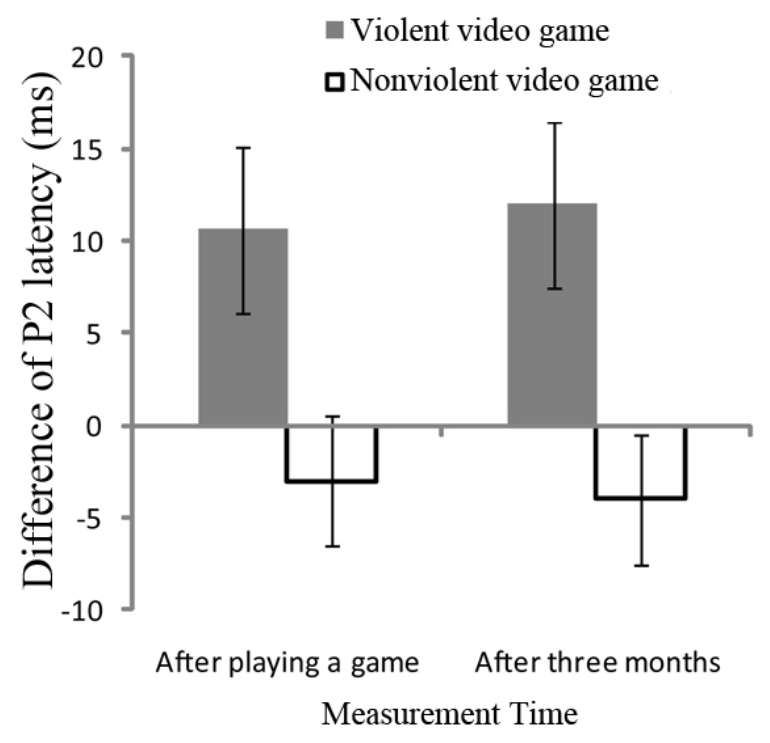

Figure 4. The effect of playing a video game on P2 latency evoked by angry faces. Each score was computed by subtracting from baseline. A positive score indicates a delay in the peak latency. Error bars represent $\pm 1 \mathrm{SE}$.

\section{Experiment 2}

\subsection{Method: Participants}

Eighteen participants (6 females and 12 males) who participated in Experiment 1 participated in Experiment 2. Four participants were unable to return to complete their follow-up assessments. Participants were paid approximately 2000 yen.

\subsection{Procedure}

Three months after the second measurement, participants returned to the laboratory and completed a third assessment. The task and questionnaire were identical to Experiment 1. Participants were fully debriefed regarding Experiments 1 and 2 and dismissed.

To test whether the effects of a violent video game remained after three months, we compared the 3-month measurements with those at baseline and the measures obtained after the initial game play period. 


\subsection{Results: BAQ}

No main effects or any interactions were significant ( $p s>.05$ ). Though not significant, physical aggression that increased after playing the violent video game tended to decrease and revert back near baseline levels ( $M s=$ 14.5, 16.8, and 15.8, SDs = 5.47, 5.67 and 6.34, respectively, see Figure 2).

\subsection{EEG}

Results showed no significant effect on the N170 after 3 months. As in Experiment 1, regarding the P2 latency evoked by angry faces, the video game $\times$ measurement time interaction was significant, $F(2,28)=5.92, p$ $=.007, \eta_{p}^{2}=.30$ (see Figure 3 and Figure 4). This interaction indicated that the latency of the P2 evoked by angry faces among participants who played the violent video game maintained its delay even after 3 months (Ms = $231 \mathrm{~ms}, 242 \mathrm{~ms}$, and $244 \mathrm{~ms}, \mathrm{SDs}=17.42,15.63$ and 18.05 respectively; see Figure 4).

\section{General Discussion}

The current study investigated the long-term effects of playing violent video games on facial expression recognition and aggressiveness. Previous research has shown that exposure to violent video games biases interpretations of emotional stimuli (Kirsh, Olczak, \& Mounts, 2005; Kirsh \& Mounts, 2007). The current study advances this literature by showing how playing a violent video game might affect neural activity associated with facial expression recognition. We observed that compared to nonviolent video game players, violent video game players showed delayed P2 latency evoked by angry faces. Meanwhile, no significant effects were found in the N170. Given that the N170 reflects categorization of facial expressions (Tamamiya \& Hiraki, 2013), playing a violent video game might not affect any sort of categorization process. According to Sharma and McKenna (2001), several studies, using both clinical and nonclinical samples, have demonstrated that emotionally laden stimuli that correspond to the emotional state of the participant produce greater interference (i.e., longer response latencies) than neutral stimuli. For instance, after being insulted, participants show attention biases toward anger-relevant stimuli (Eckhardt \& Cohen, 1997). In addition, a shift in latency for processing faces has been observed when participants are engaged in more analytic forms of facial decoding (Jemel, George, Chaby, Fiori, \& Renault, 1999). Taken together, results of the present study indicate that playing violent video games, where players are typically insulted by an antagonist, causes attention biases toward anger-relevant stimuli, which results in delayed P2 latency. Thus, after extensive exposure with playing violent video games, players might analytically process negative facial expressions to a greater extent.

Considering that video game training can improve perceptual skills (Green et al., 2010), cognitive control (Anguera et al., 2013), and amblyopia (Jeon, Lewis, \& Maurer, 2012), it is likely that playing a violent video game could modulate facial expression recognition. Moreover, observed effects on P2 latency were sustained even after a few months post playing the game. This maintenance is consistent with recent studies reporting that playing video games might induce neuroplasticity (Kühn et al., 2014), and this neuroplasticity might be preserved over long intervals (Anguera et al., 2013).

Previous studies demonstrated that playing violent video games for a few minutes immediately increases aggressiveness (Anderson \& Dill, 2000; Bushman \& Anderson, 2002). However, long-term effects of playing violent video games on aggressiveness have remained elusive. The current study observed that playing a violent video game increased physical aggressiveness even after just a few days playing the game. This finding is compatible with cross-lagged effect model analyses indicating that playing video games predicts later physical violence among players (Ihori et al., 2003). Some research suggests that playing a violent video game activates aggressive knowledge structures, which leads to increased aggressiveness (Barlett et al., 2009). When playing violent video games, players have to control characters that engage in physical behaviors (e.g., kicking and shooting antagonists). As a result, knowledge structures specifically related to physical aggression are most activated (Thori et al., 2003).

We also observed a gender difference in the effects of playing a violent video game on aggressiveness. Previous studies have been unclear as to the consistency of gender effects. For example, Bartholow and Anderson (2005) suggested that males are more affected by violent video games than are females; while, other studies have not observed this trend (see, Bushman, \& Anderson, 2002; Gentile, Lynch, Linder, \& Walsh, 2004). Bartholow and Anderson (2005) argued that because males are more aggressive than females, in general, they are 
more sensitive to aggressive cues. Thus, the effect of playing violent video games on aggressiveness might be more pronounced for males than females. Another possible explanation of the observed gender difference could be related to the video games, themselves. It is known that identifying with violent video game characters makes players more aggressive (Konijn, Bijvank, \& Bushman, 2007). The main character in the GTA game we chose is male. Thus, it might be easier for male participants to identify themselves with this violent character. This perhaps led to increased aggressiveness.

It is important to note that once game play ceased, the increased aggressiveness observed post-exposure to the violent video game tended to decrease toward participants' baseline. This finding is consistent with the notion that the effects of television violence exposure on aggression are relatively short-lived and might lack long-term consequences (e.g., Freedman, 1984). As discussed previously, playing a violent video game is thought to increase aggressiveness through the activation of knowledge structures related to aggression (Barlett et al., 2009). However, the aggression-stimulating effects of the game would only persist long after exposure if players ruminated about violence in the game (Bushman \& Gibson, 2011). In the current study, the experimenter collected the games before the second measurement, and no participants reported that they had continued to play the assigned video game thereafter. Thus, once exposure ceased, aggressive cues were no longer present, and aggressive began to subside.

The present study is the first to show the long-term effect of violent video game exposure on brain processes and facial expression recognition. There are some important limitations that should be mentioned. First, the current results were found using only one sample playing one violent video game. Though the violent video game used in the present study is a very popular game, there is a potential limit in our generalization with other forms of game exposure. Another limitation of the study relates to our participants. The current study recruited adult participants who were not regular game players. Therefore, the present data does not conclude how video game violence affects children or adults who are more avid game players. Future studies should address these limitations in order to better provide useful suggestions regarding the usefulness and limitations of certain gaming practices.

\section{Conclusion}

In conclusion, the present study suggests that playing a violent video game for a long time modulates angry face recognition and increases aggressiveness. Moreover, the follow-up study showed preservation of the modulated facial recognition, while levels of aggressiveness diminished to some extent.

\section{Acknowledgements}

All authors developed the study concept and contributed to the study design. Y.T. and G.M. performed testing and data collection. Y.T. and G.M. also performed data analyses and interpretation under the supervision of K.H. Y.T. who drafted the paper, and G.M. and H.K. provided critical revisions. All authors approved the final version of the paper for submission. This study was supported by grants from JST CREST and a Grant-in-Aid from MEXT (21118005) and JSPS (22240026).

\section{References}

Anderson, C. A., Berkowitz, L., Donnerstein, E., Huesmann, R. L., Johnson, J., Linz, D., \&Wartella, E. (2003). The Influence of Media Violence on Youth. Psychological Science in the Public Interest, 4, 81-110.

Anderson, C. A., \& Dill, K. E. (2000). Video Games and Aggressive Thoughts, Feelings, and Behavior in the Laboratory and in Life. Journal of Personality and Social Psychology, 78, 772-790. http://dx.doi.org/10.1037/0022-3514.78.4.772

Anderson, C. A., Sakamoto, A., Gentile, D. A., Ihori, N., Shibuya, A., Yukawa, S., \& Kobayashi, K. (2008). Longitudinal Effects of Violent Video Games on Aggression in Japan and the United States. Pediatrics, 122, e1067-e1072. http://dx.doi.org/10.1542/peds.2008-1425

Anderson, C. A, Shibuya, A., Ihori, N., Swing, E. L., Bushman, B. J., Sakamoto, A., \& Rothstein, H. R. (2010). Violent Video Game Effects on Aggression, Empathy, and Prosocial Behavior in Eastern and Western Countries: A Meta-Analytic Review. Psychological Bulletin, 136, 151-173. http://dx.doi.org/10.1037/a0018251

Ando, A., Soga, S., Yamasaki, K., Shimai, S., Shimada, H., Utsuki, N., \& Sakai, A. (1999). Development of the Japanese Version of the Buss-Perry Aggression Questionnaire (BAQ). The Japanese Journal of Psychology, 70, 384-392. (in Japanese). http://dx.doi.org/10.4992/jjpsy.70.384 
Anguera, J. A., Boccanfuso, J., Rintoul, J. L., Al-Hashimi, O., Faraji, F., Janowich, J., \& Gazzaley, A. (2013). Video Game Training Enhances Cognitive Control in Older Adults. Nature, 501, 97-101.

Bailey, K., West, R., \& Anderson, C. A. (2011). The Association between Chronic Exposure to Video Game Violence and Affective Picture Processing: An ERP Study. Cognitive, Affective \& Behavioral Neuroscience, 11, 259-276. http://dx.doi.org/10.3758/s13415-011-0029-y

Bartholow, B. D., Bushman, B. J., \& Sestir, M. A. (2006). Chronic Violent Video Game Exposure and Desensitization to Violence: Behavioral and Event-Related Brain Potential Data. Journal of Experimental Social Psychology, 42, 532-539. http://dx.doi.org/10.1016/j.jesp.2005.08.006

Bentin, S., Allison, T., Puce, A., Perez, E., \& McCarthy, G. (1996). Electrophysiological Studies of Face Perception in Humans. Journal of Cognitive Neuroscience, 8, 551-565. http://dx.doi.org/10.1162/jocn.1996.8.6.551

Bushman, B. J., \& Anderson, C. A. (2002). Violent Video Games and Hostile Expectations: A Test of the General Aggression Model. Personality and Social Psychology Bulletin, 78, 1679-1686. http://dx.doi.org/10.1177/014616702237649

Bushman, B. J., \& Gibson, B. (2011). Violent Video Games Cause an Increase in Aggression Long after the Game Has Been Turned off. Social Psychological and Personality Science, 2, 29-32. http://dx.doi.org/10.1177/1948550610379506

Carnagey, N. L., Anderson, C. A., \& Bushman, B. J. (2007). The Effect of Video Game Violence on Physiological Desensitization to Real-Life Violence. Journal of Experimental Social Psychology, 43, 489-496. http://dx.doi.org/10.1016/j.jesp.2006.05.003

Devilly, G. J., Callahan, P., \& Armitage, G. (2012). The Effect of Violent Videogame Playtime on Anger. Australian Psychologist, 47, 98-107. http://dx.doi.org/10.1111/j.1742-9544.2010.00008.x

Eckhardt, C. I., \& Cohen, D. J. (1997). Attention to Anger-Relevant and Irrelevant Stimuli Following Naturalistic Insult. Personality and Individual Differences, 23, 619-629. http://dx.doi.org/10.1016/S0191-8869(97)00074-3

Engelhardt, C. R., Bartholow, B. D., Kerr, G. T., \& Bushman, B. J. (2011). This Is Your Brain on Violent Video Games: Neural Desensitization to Violence Predicts Increased Aggression Following Violent Video Game Exposure. Journal of Experimental Social Psychology, 47, 1033-1036. http://dx.doi.org/10.1016/j.jesp.2011.03.027

Freedman, J. L. (1984). Effects of Television Violence on Aggressiveness. Psychological Bulletin, 96, 227-246. http://dx.doi.org/10.1037/0033-2909.96.2.227

Funk, J. B., Daldacci, H. B., Pasold, T., \& Baumgardner, J. (2004). Violence Exposure in Real-Life, Video Games, Television, Movies, and the Internet: Is There Desensitization? Journal of Adolescence, 27, 23-39. http://dx.doi.org/10.1016/j.adolescence.2003.10.005

Gentile, D. A., Lynch, P. L., Linder, J. R., \& Walsh, D. A. (2004). The Effects of Violent Video Game Habits on Adolescent Hostility, Aggressive Behaviors, and School Performance. Journal of Adolescence, 27, 5-22. http://dx.doi.org/10.1016/j.adolescence.2003.10.002

Green, C. S., Li, R., \& Bavelier, D. (2010). Perceptual Learning during Action Video Game Playing. Topics in Cognitive Science, 2, 202-216. http://dx.doi.org/10.1111/j.1756-8765.2009.01054.X

Hasan, Y., Bègue, L., Scharkow, M., \& Bushman, B. J. (2012). The More You Play, the More Aggressive You Become: A Long-Term Experimental Study of Cumulative Violent Video Game Effects on Hostile Expectations and Aggressive Behavior. Journal of Experimental Social Psychology, 49, 224-227. http://dx.doi.org/10.1016/j.jesp.2012.10.016

Horovitz, S. G., Rossion, B., Skudlarski, P., \& Gore, J. C. (2004). Parametric Design and Correlational Analyses Help Integrating fMRI and Electrophysiological Data during Face Processing. NeuroImage, 22, 1587-1595. http://dx.doi.org/10.1016/j.neuroimage.2004.04.018

Ihori, N., Sakamoto, A., Kobayashi, K., \& Kimura, H. (2003). A Panel Study on Causal Relationships between Video Game Use and Aggressiveness in Elementary School Children: Effects on Physical Violence. Simulation \& Gaming, 13, $139-148$. (in Japanese)

Jemel, B., George, N., Chaby, L., Fiori, N., \& Renault, B. (1999). Differential Processing of Part-to-Whole and Part-to-Part Face Priming: An ERP Study. NeuroReport, 10, 1069-1075. http://dx.doi.org/10.1097/00001756-199904060-00031

Jeon, S. T., Lewis, T. L., \& Maurer, D. (2012). The Effect of Video Game Training on the Vision of Adults with Bilateral Deprivation Amblyopia. Seeing and Perceiving, 25, 493-520. http://dx.doi.org/10.1163/18784763-00002391

Kirsh, S. J., \& Mounts, J. R. W. (2007). Violent Video Game Play Impacts Facial Emotion Recognition. Aggressive Behavior, 33, 353-358. http://dx.doi.org/10.1002/ab.20191

Kirsh, S. J., Mounts, J. R. W., \& Olczak, P. V. (2006). Violent Media Consumption and the Recognition of Dynamic Facial Expressions. Journal of Interpersonal Violence, 21, 571-584. http://dx.doi.org/10.1177/0886260506286840

Kirsh, S. J., Olczak, P. V., \& Mounts, J. R. W. (2005). Violent Video Games Induce an Affect Processing Bias. Media Psychology, 7, 239-250. http://dx.doi.org/10.1207/S1532785XMEP0703_1

Kühn, S., Gleich, T., Lorenz, R. C., Lindenberger, U., \& Gallinat, J. (2014). Playing Super Mario Induces Structural Brain 
Plasticity: Gray Matter Changes Resulting from Training with a Commercial Video Game. Molecular Psychiatry, 19, 265271. http://dx.doi.org/10.1038/mp.2013.120

Lang, A. (2006). Using the Limited Capacity Model of Motivated Mediated Message Processing to Design Effective Cancer Communication Messages. Journal of Communication, 56, S57-S80. http://dx.doi.org/10.1111/j.1460-2466.2006.00283.x

Latinus, M., \& Taylor, M. J. (2005). Holistic Processing of Faces: Learning Effects with Mooney Faces. Journal of Cognitive Neuroscience, 17, 1316-1327. http://dx.doi.org/10.1162/0898929055002490

Sharma, D., \& McKenna, F. P. (2001). The Role of Time Pressure on the Emotional Stroop Task. British Journal of Psychology, 92, 471-481. http://dx.doi.org/10.1348/000712601162293

Staude-Müller, F., Bliesener, T., \& Luthman, S. (2008). Hostile and Hardened? An Experimental Study on (De-)Sensitization to Violence and Suffering through Playing Video Games. Swiss Journal of Psychology, 67, 41-50. http://dx.doi.org/10.1024/1421-0185.67.1.41

Tamamiya, Y., \& Hiraki, K. (2013). Individual Differences in the Recognition of Facial Expressions: An Event-Related Potentials Study. PLoS ONE, 8, Article ID: e57325. http://dx.doi.org/10.1371/journal.pone.0057325

Wallenius, M., \& Punamäki, R. (2008). Digital Game Violence and Direct Aggression in Adolescence: A Longitudinal Study of the Roles of Sex, Age, and Parent-Child Communication. Journal of Applied Developmental Psychology, 29, $286-294$. http://dx.doi.org/10.1016/j.appdev.2008.04.010

Weber, R., Ritterfeld, U., \& Mathiak, K. (2006). Does Playing Violent Video Games Induce Aggression? Empirical Evidence of a Functional Magnetic Resonance Imaging Study. Media Psychology, 8, 39-60.

http://dx.doi.org/10.1207/S1532785XMEP0801_4 
Scientific Research Publishing (SCIRP) is one of the largest Open Access journal publishers. It is currently publishing more than 200 open access, online, peer-reviewed journals covering a wide range of academic disciplines. SCIRP serves the worldwide academic communities and contributes to the progress and application of science with its publication.

Other selected journals from SCIRP are listed as below. Submit your manuscript to us via either submit@scirp.org or Online Submission Portal.
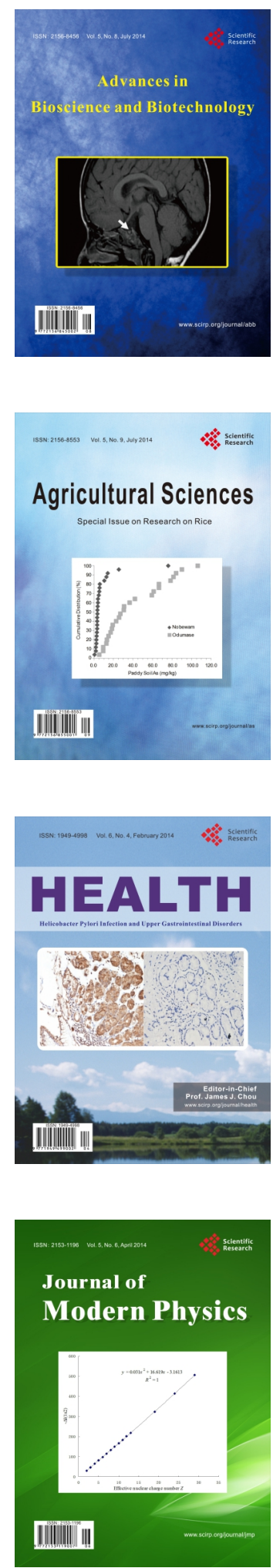
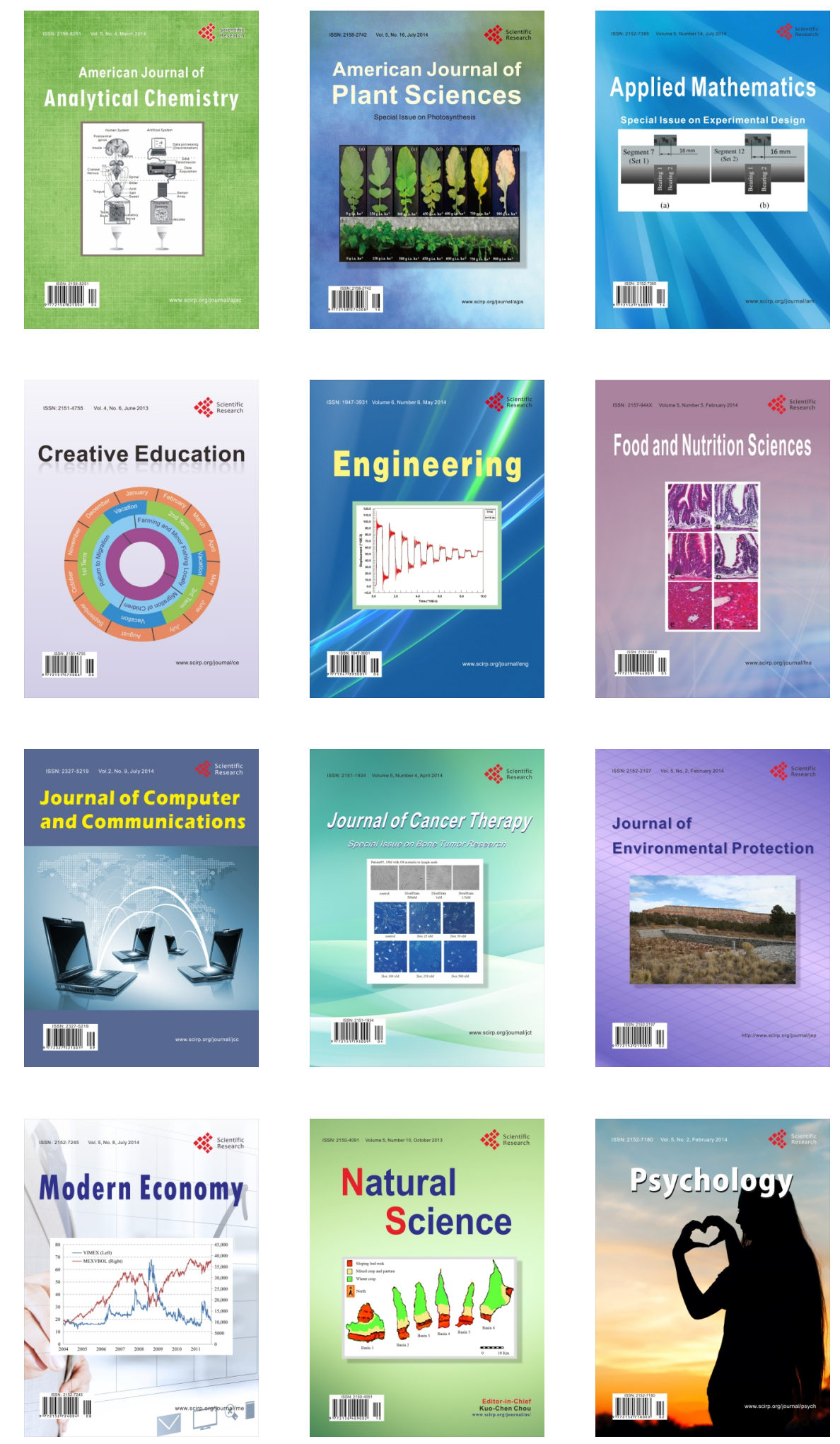